\title{
NUMERICAL ANALYSIS OF THE STRAIN DISTRIBUTION UNDERNEATH THE SURFACE OF POLYETHYLENE FLAT AND SPHERICAL INSERTS WITH METAL SLED
}

\author{
Marcin Nabrdalik \\ Institute of Mechanical Technology, Czestochowa University of Technology \\ Czestochowa, Poland \\ marcin@iop.pcz.pl
}

\begin{abstract}
Most of the mechanical failures in alloplasty are caused by material fatigue. To cut down the risk of it, we can either increase the fatigue resistance of the material or decrease the load strain. All presented numerical calculations allow to draw quality conclusions concerning the influence of some parameters of endoprostheses on the values of stress and strain that are formed in polyethylene inserts.
\end{abstract}

Keywords: strain, endoprosthesis

\section{The strain occurring in polyethylene inserts submitted to load}

The value of material strain in polyethylene inserts is a very important issue. UHMWPE polyethylene is the weakest point of endoprosthesis, which is why it is important to present the reduced strain distribution as well as the strain of the inserts.

Hooke's law for general, 3-dimensional strain distribution for isotropic material can be presented as $[1,2]$ :

- For linear deformation

$$
\begin{aligned}
& \varepsilon_{x}=\frac{1}{E}\left[\sigma_{x}-v\left(\sigma_{y}+\sigma_{z}\right)\right] \\
& \varepsilon_{y}=\frac{1}{E}\left[\sigma_{y}-v\left(\sigma_{z}+\sigma_{x}\right)\right] \\
& \varepsilon_{z}=\frac{1}{E}\left[\sigma_{z}-v\left(\sigma_{x}-\sigma_{y}\right)\right]
\end{aligned}
$$

- For angular deformation

$$
\begin{aligned}
& \Upsilon_{x y}=\frac{\tau_{x y}}{G} \\
& \Upsilon_{y z}=\frac{\tau_{y z}}{G} \\
& \Upsilon_{x z}=\frac{\tau_{x z}}{G}
\end{aligned}
$$


where:

$\varepsilon$ - linear strain

$\sigma$ - linear stress

$\gamma$ - angular strain

$\tau$ - angular stress

G - elasticity coefficient, Kirchhoff's modulus.

In general tensor notation (for anisotropic material) as a proportional coefficient the stiffness tensor $\mathrm{c}$ is used

$$
\sigma^{i j}=c^{i j k l} \varepsilon_{k l}
$$

Stiffness tensor for Hooke's law can be noted with Lamé's constant as:

$$
c^{\mathrm{ijkl}}=\lambda \mathrm{g}^{\mathrm{ij}} \mathrm{g}^{\mathrm{kl}}+2 \mu \cdot \delta_{\mathrm{i}}^{\mathrm{k}} \delta_{\mathrm{j}}^{\mathrm{l}}
$$

where:

$\lambda$ and $\mu$ - Lamé's constants

$g$ - metric tensor

$\delta$ - Kronecker's delta.

\section{Assumptions for calculations}

The calculations were based on the following assumptions, defining the influence of important factors on the stress:

- the influence of cross-section radius of metal sled of endoprosthesis on the value of strain in the contact area of the above elements;

- the influence of the kind of contact on the value of the strain;

Kinds of contacts between elements of endoprosthesis are:

- point contact, when loaded elements touch first and then it gradually transforms into linear contact;

- surface contact, when sled works with spherical polyethylene insert [3-5].

The elements were submitted to a load similar to the one occurring in the real knee joint. A numerical analysis was conducted with the ADINA 7.5.1. The obtained results may be used to create the plan of the foreseen distribution of wear of particular areas of sleds and polyethylene inserts, before they are used in endoprostheses.

\section{Material data}

The calculations were conducted for flat and spherical inserts made of medical UHMWPE of higher density and $8 \mathrm{~mm}$ thick. Regular load for endoprostheses is 
$1500 \mathrm{~N}$, and for calculations two different geometrical sleds were taken of $17 \mathrm{~mm}$ and $27 \mathrm{~mm}$ values of cross-section radius.

It was assumed that all materials used in models (medical alloy of titanium Ti6Al4V, UHMWPE polyethylene) are linearly elastic. Additionally they were isotropic with constant mechanical features.

The values of mechanical features, such as the elasticity modulus and Poisson's coefficient, are presented in Table 1.

Table 1

Mechanical features and specific weight of the materials of endoprostheses [3]

\begin{tabular}{|c|c|c|c|}
\hline & $\begin{array}{c}\text { Young's modulus } \\
\text { E [MPa] }\end{array}$ & $\begin{array}{c}\text { Poisson's coefficient } \\
v\end{array}$ & $\begin{array}{c}\text { Specific weight } \rho \\
{\left[\mathrm{kg} / \mathrm{m}^{3}\right]}\end{array}$ \\
\hline Ti6Al4V & $1,1 \cdot 10^{5}$ & 0.3 & 4500 \\
\hline UHMWPE & 1000 & 0.4 & 960 \\
\hline
\end{tabular}

The calculations are based on a regular simplified load model, where normal force is put to the upper surface of the sled. The load submitted to the numerical models was the result of the interaction between the joint surface of femoral bone and implanted polyethylene insert. The above model is simplified as the research concerned the stress and strain in polyethylene insert, which is the weakest element of endoprostheses and is the most responsible for the endoprosthesis durability.

All the below models were constructed in the ADINA System 7.5.1 based on the Finite Elements Method. The model with linear contact consists of 4312 nodes: There are two groups of elements in it:

- the first group consists of 1600 eight-nodes elements (3-D solid elements) simulating metal sled.

- the second group consists of 2000 eight-nodes elements (3-D solid elements) simulating polyethylene insert.

The contact area 3-D between proper elements of the sled and the insert was modeled as the copy of the real area of the interaction between both elements of endoprostheses.

\section{The analysis of the strain in the set sled - flat insert and set sled - spherical insert in the endoprosthesis}

The results presented in Figures 1-5, show the values of strains in cross- and along-section of the analysed numerical models. 


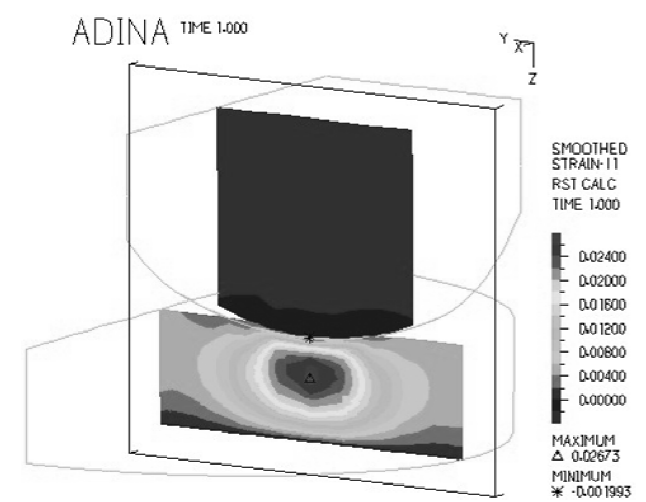

Fig. 1. The strain distribution of the material occurring underneath the surface of flat polyethylene insert cooperating with the metal sled. Cross-section of the model.

A sled with cross radius of $27 \mathrm{~mm}$. Load $1500 \mathrm{~N}$

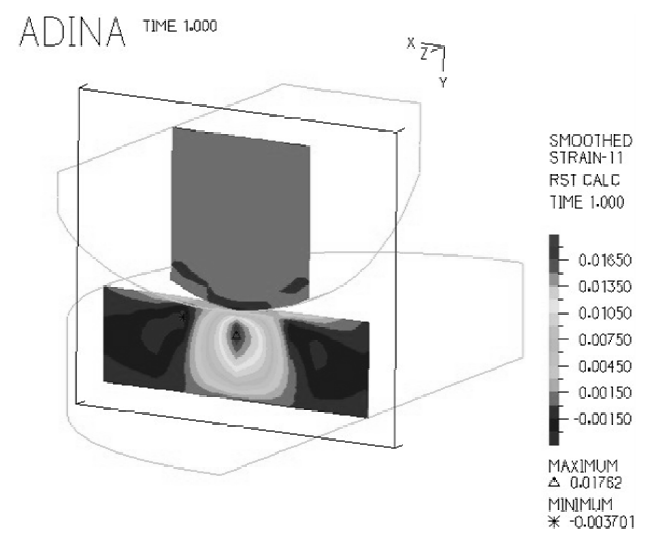

Fig. 2. The strain distribution of the material occurring underneath the surface of spherical polyethylene insert cooperating with metal sled. Cross-section of the model.

A sled with cross radius of $27 \mathrm{~mm}$. Load $1500 \mathrm{~N}$

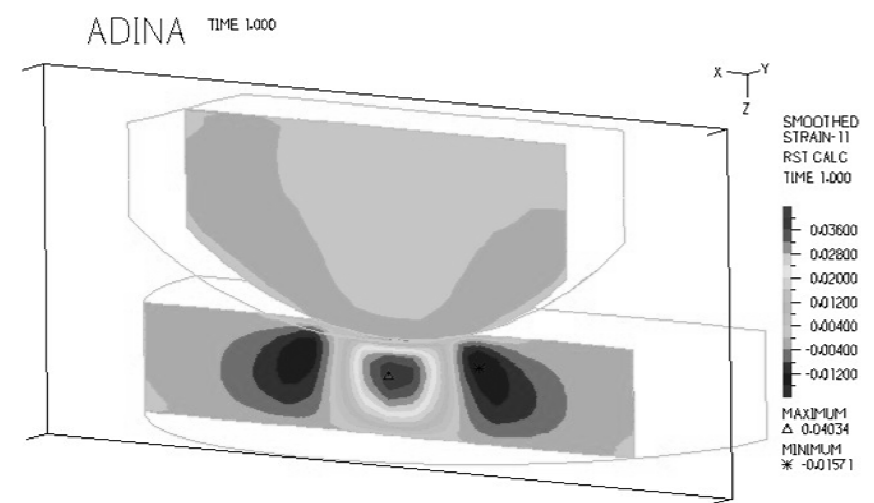

Fig. 3. The strain distribution of the material occurring underneath the surface of flat polyethylene insert cooperating with a metal sled. Along-section of the model. A sled with cross radius of $27 \mathrm{~mm}$. Load $1500 \mathrm{~N}$ 


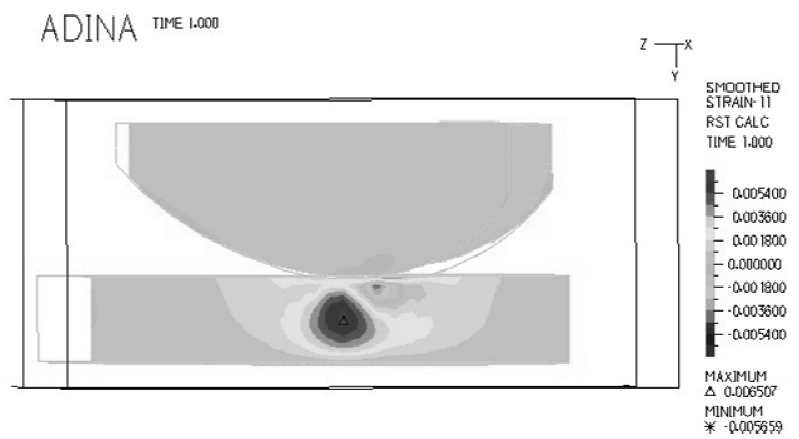

Fig. 4. The strain distribution of the material occurring underneath the surface of a flat polyethylene insert cooperating with a metal sled. Along-section of the model. A sled with cross radius of $17 \mathrm{~mm}$. Load $1500 \mathrm{~N}$

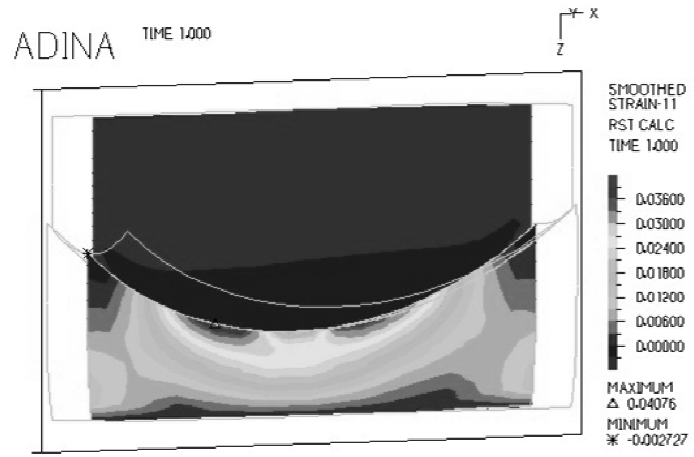

Fig. 5. The strain distribution of the material occurring underneath the surface of a spherical polyethylene insert cooperating with metal sled. Along-section of the model. A sled with cross radius of $27 \mathrm{~mm}$. Load $1500 \mathrm{~N}$

\section{The influence of geometry and contact area surface on the value of the strain}

All the results show clearly that most of the strain in the endoprostheses is concentrated in the polyethylene insert right underneath the surface where both elements touch. The strain distribution is different in both kinds of inserts. The results confirmed the theory and the strain is stronger in the flat insert than in the spherical one. Additionally, in the spherical insert the distribution is more regular than the one in the flat insert. As for the influence of the cross-section radius it is clear that the sled with a smaller one, $17 \mathrm{~mm}$, generates higher values of the strain than the sled of a $27 \mathrm{~mm}$ radius.

\section{The conclusions drawn from the numerical simulations on knee joint endoprosthesis concerning the strain distribution in the implant:}

1. The contact strain values can be decreased by proper adjustment of cooperating surfaces and substituting the linear contact by the surface one. 
2. The conducted tests on stress pattern in sled - insert pair show that flat inserts generate a higher strain than the spherical ones.

3. The results present the contact areas and the fields of highest values of stress and displacement, and where the metal elements' prints in the polyethylene. It makes it possible to define particular endoprosthesis as far as the stress it generates is concerned, and furthermore - foresee how it will behave later on.

4. The calculations proved that spherical polyethylene inserts decreases material strain concentration and makes it more regular.

5. When the sled is of $17 \mathrm{~mm}$ cross-section radius, the strain and stress concentration in the insert is much higher than when the radius is of $27 \mathrm{~mm}$. It proves that the value of the cross-section radius is critically important.

\section{References}

[1] Gierzyńska-Dolna M., Biotribologia. Wydawnictwo Politechniki Częstochowskiej, Częstochowa 2002.

[2] Gierzyńska-Dolna M., Kubacki J., Wieczorek A., Tatar K., Mechanizm zużycia endoprotezy saneczkowej stawu kolanowego, Biology of Sport 1998, 112-119.

[3] Marciniak J., Biomateriały, Wydawnictwo Politechniki Śląskiej, Gliwice 2002.

[4] Zakrzewski M., Zawadzki J., Wytrzymałość materiałów, Wrocław 1975.

[5] Zienkiewicz O.C., Metoda elementów skończonych, Arkady, Warszawa 1972. 